\title{
Optimization and evaluation of operation strategies for regional distributed energy system
}

\author{
Jingyi Yuan ${ }^{1}$, Miao $\mathrm{Li}^{1,}{ }^{,}$, Xiaoyu $\mathrm{Liu}^{2}$, and $k u n \mathrm{Xu}^{3}$ \\ ${ }^{1}$ School of Mechanical Engineering and Automation, Dalian Polytechnic University, Dalian, 116034, China; limiaolaile@163.com \\ ${ }^{2}$ Key Laboratory of Ocean Energy Utilization and Energy Conservation of Ministry of Education, Dalian University of Technology, \\ Dalian, 116024, China \\ ${ }^{3}$ Kuka flexible systems (Shanghai) co., LTD, 200135, China
}

\begin{abstract}
With the development of energy technologies, the electricity, cooling and heating are tightly connected to improve the overall efficiency of distributed energy systems. These systems satisfy simultaneously different energy demands at building level (hotels, offices and residential buildings). The optimal capacity of technologies from numerous alternatives and optimal operating strategy as well as electricity network connection was investigated in this paper in order to achieve economic and environmental gains. A mixed integer linear programming model was also used for multi-objective optimization to minimize total cost and pollutant emissions. The results show that distributed energy system with electricity network as well as real time control can realize the better performance through multioptimization from regional viewpoint. However, the results are on the contrary aiming at individual hotels and offices. The performance advancement of this system can only be reflected in residential buildings.
\end{abstract}

\section{Nonmenclature}

\begin{tabular}{|cc|}
\hline Abbreviations & \\
DES & Distributed energy system \\
PGU & Power generation unit \\
EN & Electricity network \\
CONT & Control \\
COST & Economic effect \\
EEF & Environmental effect \\
CON & Conventional energy system \\
Symbols & equipments \\
eq & purchase \\
pur & weighting factors \\
$\beta$ & weighting factors \\
$\tau$ & \\
\hline
\end{tabular}

\section{Introduction}

Recently, a large proportion of energy use is occupied by buildings and the building energy use is extremely important for energy consumption analysis in urban area. But there are still many contradiction of conventional energy system due to its high investment, unfriendly environment and low energy efficiency. Therefore, with the development of energy technologies in distributed energy system, the electricity, cooling and heating are tightly linked to overcome above shortcomings and improve the overall efficiency. Furthermore distributed energy system integrated with electricity network is a promising method that electricity can be generated from individually connected buildings instead of a central power plant. However, the introduction of this system also results in more complex requirements for design and operation. It is necessary to determine the optimal capacity of equipments from numerous alternatives and obtain optimal operating strategy in order to achieve economic and environmental advancements [1].

Distributed energy systems optimization and evaluation is a broad topic which lately has received a lot of attention. Soderman et al. [2] developed a MILP model of a distributed energy system with district heating pipelines to minimize total cost. Omu et al. [3] presented an optimization model to select optimal sets of technologies with predefined capacities, and operation of distributed network (electrical and heating). Mehleri et al. [4] applied a MILP model for the optimal design of distributed energy systems with heating network according to the case study for three design periods. Liu et al. [5] performed no optimization and just analyzed the performance of energy technologies on district electric and heating network. Yang et al. [6] developed a MILP model for only 4 buildings to optimize their design and operation of distributed energy systems with district heating from economic point.

In conclusion, most previous papers deal with the design optimization of distributed energy system integrated with network, which not put emphasis on the optimal operation schedules considering real-time control.

This paper presents a multi-objective MILP model that combines a distributed energy system with electricity network. The model can determine the optimal sets of technologies and the optimal operation

\footnotetext{
* Corresponding author: limiaolaile@,163.com
} 
schedule with real time intelligent control. Furthermore, the economic and environmental performance of representative building is individually evaluated and through comprehensive assessment.

\section{Case study}

Figures and tables, as originals of good quality and well contrasted, are to be in their final form, ready for reproduction, pasted in the appropriate place in the text. Try to ensure that the size of the text in your figures is approximately the same size as the main text (10 point). Try to ensure that lines are no thinner than 0.25 point. The model in respective winter day was used to hotels, offices and residential buildings located in Dalian, China. In this optimization, a comparative analysis was studied through the following scenarios. The model presented in this paper has been optimized for the three scenarios:

Scenario 1 (DES): In this region, the majority of energy demand including electricity, heating and cooling systems can be satisfied by the installed DES in each producer, for a small part from boilers and utility grids.

Scenario 2 (DES+EN): In this scenario, electricity network was added to DES. The electricity can be generated from individually connected buildings and then excess electricity can be exchanged from other buildings.

Scenario 3 (DES+EN+CONT): In this scenario, except for electricity network was added to DES, realtime control of actual electricity demand was used to optimize operating schedule of DES and each building can exchange electricity with other buildings through intelligent control.

\section{Mathematical model}

\subsection{Economic objective}

The total cost COSTDES consists of equipment and network capital and installation cost $\left(\mathrm{C}_{\mathrm{iv}, \mathrm{eq}}\right.$ and $\left.\mathrm{C}_{\mathrm{iv}, \text { net }}\right)$, operation and maintenance $(\mathrm{OM}) \operatorname{cost}\left(\mathrm{C}_{\mathrm{om}, \mathrm{eq}}\right.$ and $\left.\mathrm{C}_{\text {om,net }}\right)$, fuel and grid electricity purchased cost $\left(\mathrm{C}_{\text {pur,fuel }}\right.$ and $\mathrm{C}_{\text {pur,grid }}$ ) $[7,8]$.

$$
\begin{aligned}
& C O S T_{D E S}= C_{i v, \text { eq }}+C_{i v, \text { net }}+C_{\text {om,eq }}+C_{\text {om,eq }}+C_{\text {pur,fuel }}+ \\
& C_{\text {pur,grid }}
\end{aligned}
$$

\subsection{Environmental objective}

Recently, pollutant emissions have received a lot of attention considering distributed energy system. Environment effect (EEF) including global warming effect (GWE), acidification effect (AE) and PM2.5 emission effect (RE), is calculated as:

$$
E E F=\beta_{1} G W E+\beta_{2} A E+\beta_{3} R E
$$

$\beta_{1}, \beta_{2}, \beta_{3}$ is assumed as $1 / 3$, respectively, referring to $[9,10]$.

\subsection{Multi-objective optimization}

Referring to the economic and environmental objective function, a multi-objective function $\mathrm{T}$ is formulated as a weighted sum of the cost savings, COST, and the pollution emission reduction, EEF, to be maximized as follows [11]:

$$
T=\operatorname{MAX}\left\{\tau_{1} \frac{C O S T_{C O N}-C O S T_{D E S}}{C O S T_{C O N}}+\tau \frac{E E F_{C O N}-E E F_{D E S}}{E E F_{C O N}}\right\}
$$

CON means convention energy system, in which the electricity demand is satisfied by utility grid, heating demand by the gas boilers and cooling load by the electric chiller. No DES technology or electricity network was considered. $\tau_{1}$ and $\tau_{2}$ is assumed as $1 / 2$, respectively.

\section{Results and Discussion}

A comparative study has been conducted to evaluate the performance of integrating distributed generation system with electricity network among buildings as well as real time control. Fig.1 illustrates multi-objective values of the economic saving and pollutant emission reduction in scenario 1 (only DES), scenario 2 (with electricity network but not with control) and scenario 3 (with electricity network and real time control), respectively. It can be found from Figure 1 that, in general, the objective reduction values in the three scenarios have the same variation tendency. It can be also noted that the adoption of the DES+EN+CONT in scenarios 3 allows the higher objective values. However, the overall conclusion was just obtained through comprehensive assessment from regional viewpoint.

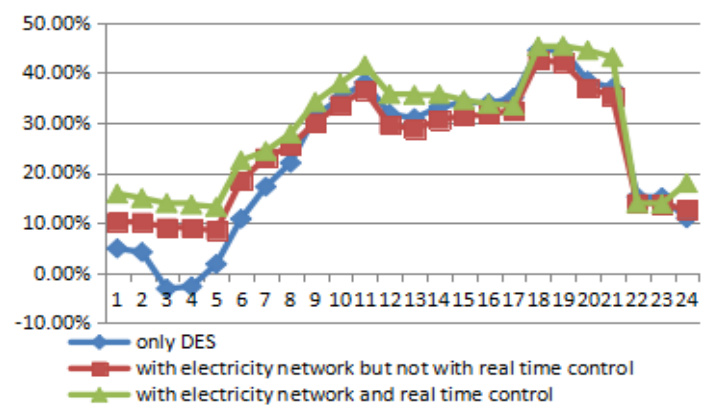

Fig. 1. The objective values in the three scenarios in typical winter days.

The performance of individual buildings (hotels) was evaluated in Figure 2. From Figure 2, the phenomenon was different from the results in Figure 1. The economic performance, environmental performance and overall performance through multi-objective optimization of hotels in scenario 3 allows the lowest values at most of the time. This implies that distributed energy system integrated with electricity network and real time control is not the best approach simply from hotel viewpoint. 
This design and operation strategy is more suitable for a regional level.

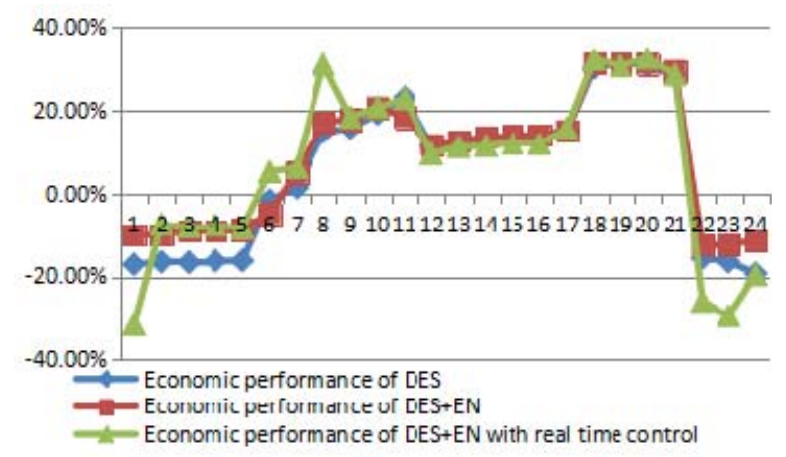

(a)

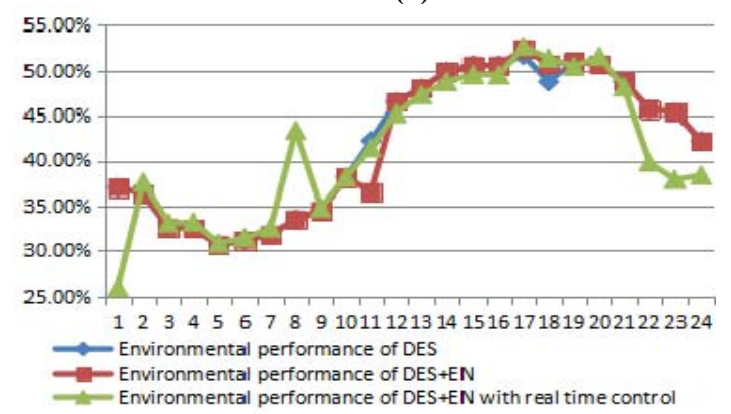

(b)

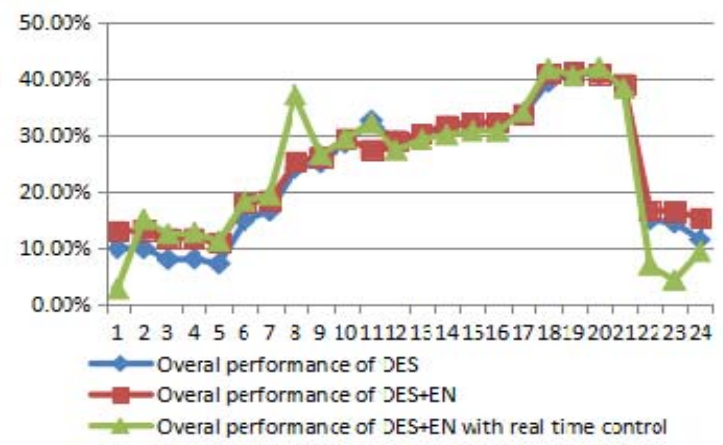

(c)

Fig. 2. The economic (a), environmental (b) and multiobjective (c) values of hotels in the three scenarios in typical winter day.

Figure 3 shows the various optimization results of offices in winter day. It can be seen that, scenario 3 still cannot obtain better performance compared with other two scenarios in the daytime. However, the performances of the DES+EN+CONT in scenarios 3 were conversely highest in the night time (see Figure 3). It is also noted that, in the daytime, scenario 2 (with electricity network but not real time control) presented a better performance values. The reason is that without real time control more excess electricity is generated by PGU in avoidance to purchased electricity from utility for its high price. The supplement of electricity can also be exchanged to other buildings.

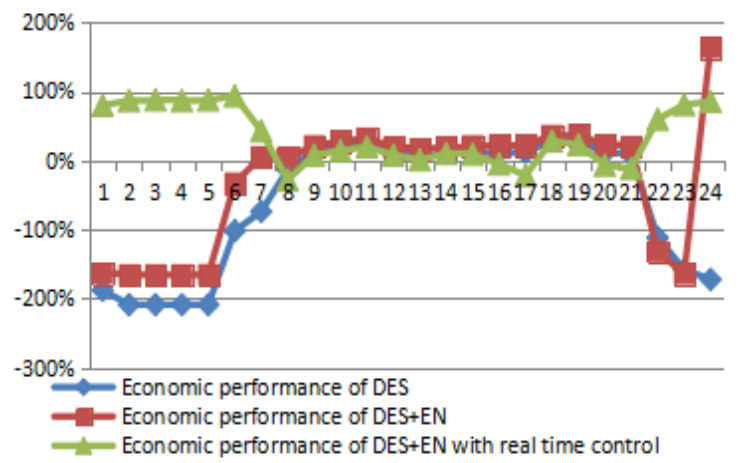

(a)

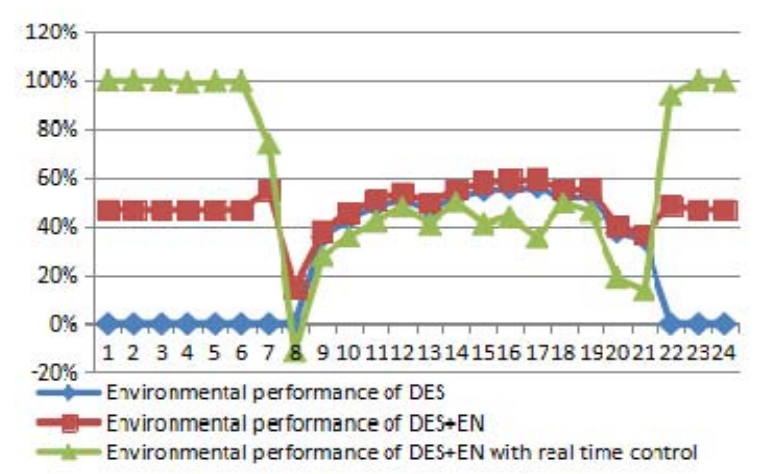

(b)

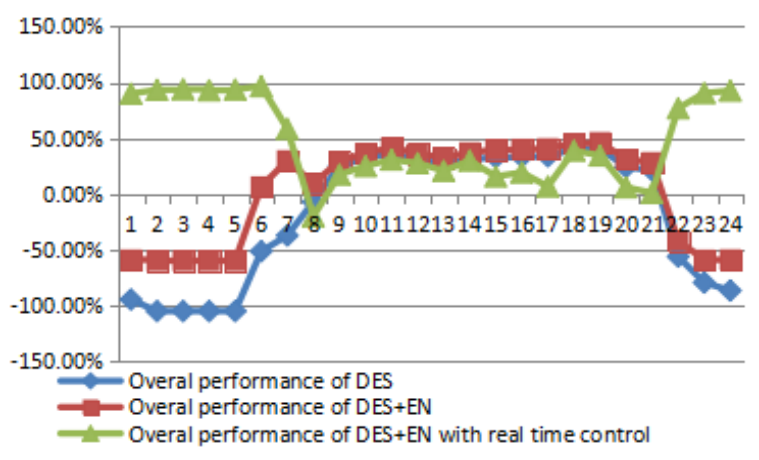

(c)

Fig. 3. The economic (a), environmental (b) and multiobjective (c) values of offices in the three scenarios in typical winter day.

The performance values of residential buildings in the three scenarios in typical winter day were shown in Figure 4.

From Figure 4, the values of scenario 1 and scenario 2 have the same variation tendency. And scenario 3 presented a larger advantage compared with other two scenarios from $8 \mathrm{am}$ to $21 \mathrm{pm}$. This is because in this period more electricity demand of residential buildings is transferred from offices and hotels. And PGU is out of work at most of time. 


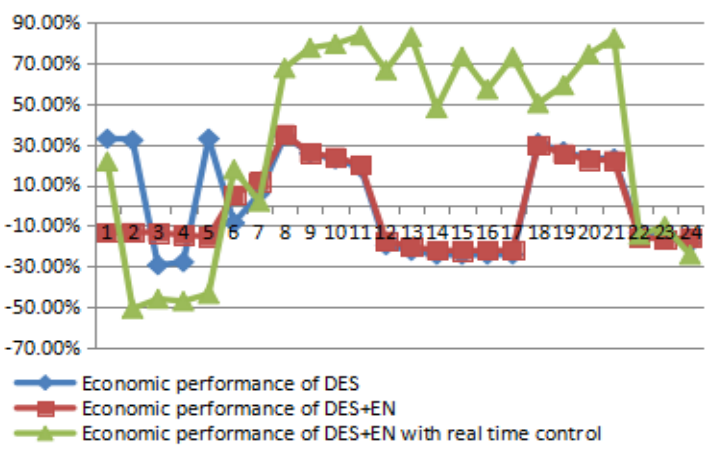

(a)

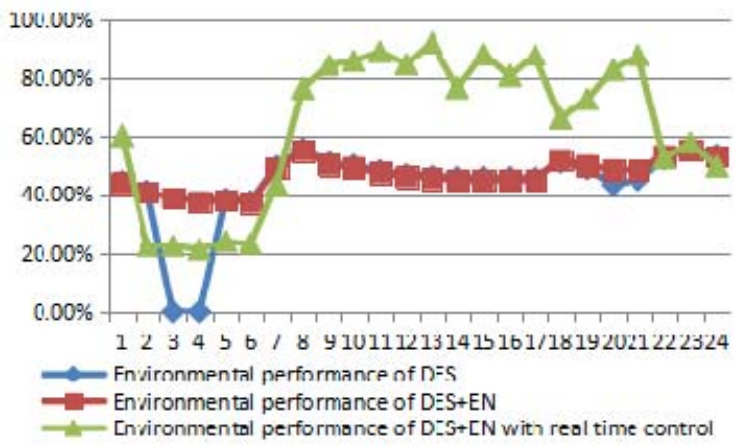

(b)

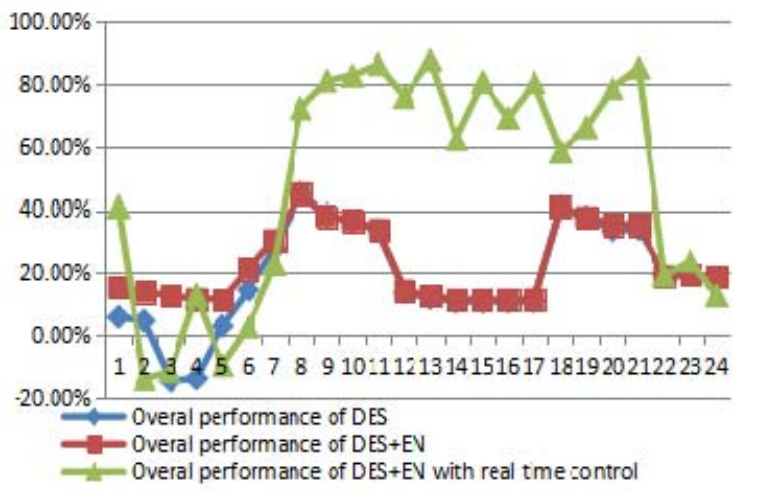

(c)

Fig. 4. The economic (a), environmental (b) and multiobjective (c) values of residential buildings in the three scenarios in typical winter day.

\section{Conclusion}

A MILP optimization model of a distributed energy system was developed. Multi-objective optimization of total costs and pollutant emissions was performed. The model was used to three scenarios to determine the benefits of the system.

In general, from regional viewpoint, distributed energy system with electricity network as well as real time control (DES+EN+CONT in scenario 3) can realize the better economic, environmental and overall performance through multi-optimization. However, from individual buildings viewpoint, scenario 3 cannot be suitable for hotels and offices but be beneficial to residential buildings. While distributed energy system with electricity network (DES+EN in scenario 2) reflected its performance advantage in hotels and offices.

\section{Acknowledgements}

This research was funded by National Natural Science Foundation of China (71603035) and Foundation of Liaoning province (J2019047).

\section{References}

1. Morvaj B, Evins R, Carmeliet J. Optimising urban energy systems: simultaneous system sizing, operation and district heating network layout. Energy 2016; 116:619-636.

2. Soderman J, Pettersson F. Structural and operational optimization of distributed energy systems. Appl Therm Eng 2006; 26:1400-8.

3. Omu A, Choudhary R, Boies A. Distributed energy resource system optimization using mixed integer linear programming. Energy Policy 2013; 61:249-66.

4. Mehleri ED, Sarimveis H, Markatos NC, Papageorgiou LG. Optimal design and operation of distributed enengy systems: application to Greek residential sector. Renew Energy 2013; 51:331-42.

5. Liu $\mathrm{X}, \mathrm{Wu} \mathrm{J}$, Jenkins $\mathrm{N}$, Bagdanavicius A. Combined analysis of electricity and heat networks. Appl Energy 2016; 162:1238-50.

6. Yang Y, Zhang S, Xiao Y. Optimal design of distributed energy resource systems coupled with energy distribution networks. Energy 2015;85:43348.

7. Somma, M.D.; Yan.B.; Bianco, N.; Luh, P. B.; Graditi, G.; Mongibello, L.; Naso.V. Multi-objective operation optimization of a Distributed Energy system for a large-scale utility customer. Applied thermal engineering 2016, $101: 752-761$.

8. Lesse, J.A.;Su, X. Design of an economically efficient feed-in tariff structure for renewable energy development. Energy Policy 2008; 36(3):981-90.

9. Jing, Y.Y.; Bai, H.; Wang, J.J. Multi-objective optimization design and operation strategy analysis of BCHP system based on life cycle assessment. Energy 2012; 37(1):405-416.

10. Li, M,; Mu, H.L.; Li. N.; Ma,B.Y. Optimal design and operation strategy for integrated evaluation of CCHP (combined cooling heating and power) system. Energy 2016,99 : 202-220.

11. Rieder,A.; Christidis, A.; Tsatsaronis, G. Multi criteria dynamic design optimization of a small scale distributed energy system. Energy 2014;74:230-9. 